\title{
Cone Photoreceptors in Bass Retina Use Two Connexins to Mediate Electrical Coupling
}

\author{
John O'Brien, ${ }^{1,2}$ H. Bao Nguyen, ${ }^{1}$ and Stephen L. Mills ${ }^{1,2}$ \\ ${ }^{1}$ Department of Ophthalmology and Visual Science and ${ }^{2}$ Graduate School of Biomedical Sciences, University of Texas Health Science Center, Houston, \\ Texas 77030
}

\begin{abstract}
Electrical coupling via gap junctions is a common property of CNS neurons. In retinal photoreceptors, coupling plays important roles in noise filtering, intensity coding, and spatial processing. In many vertebrates, coupling is regulated during the course of light adaptation. To understand the mechanisms of this regulation, we studied photoreceptor gap junction proteins. We found that two connexins were expressed in bass cone photoreceptors. Connexin 35 (Cx35) mRNA was present in many cell types, including photoreceptors and amacrine, bipolar, and a few ganglion cells. Antibodies to $\mathrm{Cx} 35$ labeled abundant gap junctions in both the inner and outer plexiform layers. In the outer plexiform layer, numerous plaques colocalized with cone telodendria at crossing contacts and tip-to-tip contacts. Cx34.7 mRNA was found predominantly in the photoreceptor layer, primarily in cones. Cx34.7 immunolabeling was limited to small plaques immediately beneath cone pedicles and did not colocalize with $\mathrm{Cx} 35$. Cx34.7 plaques were associated with a dense complex of cone membrane beneath the pedicles, including apparent contacts between telodendria and cone pedicles. Tracer coupling studies of the connexins expressed in HeLa cells showed that coupling through Cx35 gap junctions was reduced by protein kinase A (PKA) activation and enhanced by PKA inhibition through a greater than fivefold activity range. Cx34.7 was too poorly expressed to study. PKA regulation suggests that coupling through $\mathrm{Cx} 35$ gap junctions can be controlled dynamically through dopamine receptor pathways during light adaptation. If Cx34.7 forms functional cell-cell channels between cones, it would provide a physically separate pathway for electrical coupling.
\end{abstract}

Key words: gap junction; cAMP; photoreceptors; phosphorylation; protein kinase A; bipolar cell

\section{Introduction}

Gap junctions play an integral role in neuronal circuitry throughout the CNS. Ionic flow through the intercellular channels mediates electrical coupling between the participating cells, providing for variable sharing of electrical signals. Electrical coupling supports circuit-specific coordination of firing activity of neurons (MacVicar and Dudek, 1981; Gibson et al., 1999; Veruki and Hartveit, 2002) and contributes to gamma frequency and highfrequency oscillations (Draguhn et al., 1998; Deans et al., 2001; Hormuzdi et al., 2001; Maier et al., 2002).

In the retina, electrical coupling is an important determinant of receptive field size in some neurons, such as horizontal cells (cf. Teranishi et al., 1983; Piccolino et al., 1984) and some amacrine cells (Bloomfield et al., 1997). Furthermore, modulation of the extent of gap junctional coupling during visual adaptation has

Received July 17, 2003; revised May 7, 2004; accepted May 7, 2004.

This research was supported by National Eye Institute Grants EY12857, EY10121, and EY10608 and Research to Prevent Blindness. We thank Justin Lyon and James Ekstrom for donation of hybrid bass used for this study, Dr. Wei Li and Cheryl Mitchell for assistance with microscopy and cell culture, and Drs. Steve Massey, Samuel Wu, and Ulrike Janssen-Bienhold for helpful discussions.

Correspondence should be addressed to John 0'Brien, Department of Ophthalmology and Visual Science, University of Texas Health Science Center, Houston, 6431 Fannin Street, MSB 7.024, Houston, TX 77030. E-mail: john.obrien@uth.tmc.edu.

H. B. Nguyen's present address: Department of Oncology, Johns Hopkins University, Baltimore, MD 21231. DOI:10.1523/JNEUROSCI.1248-04.2004

Copyright $\odot 2004$ Society for Neuroscience $\quad 0270-6474 / 04 / 245632-11 \$ 15.00 / 0$ important consequences for the network properties of these neurons.

Photoreceptors of many vertebrates are coupled by gap junctions (Raviola and Gilula, 1973; Witkovsky et al., 1974; Fujisawa et al., 1976; Gold and Dowling, 1979). Rod-rod, cone-cone, and rod-cone gap junctions have all been observed. The function of photoreceptor gap junctions appears to be complex. Gap junctions between photoreceptors spread responses through adjacent terminals, improving the signal/noise ratio under many conditions (Schwartz, 1975a; Lamb and Simon, 1976) and expanding the voltage range through which a synaptic response is possible (Attwell et al., 1987). Rod-cone gap junctions also provide a pathway through which high-sensitivity rod signals may enter the cone pathways and chromatic or high-frequency cone signals may enter the rod pathway (Schwartz, 1975b; Wu and Yang, 1988; Krizaj et al., 1998).

Rod-cone coupling has been reported to increase with light adaptation (Yang and $\mathrm{Wu}, 1989$ ) or dopamine $\mathrm{D}_{2}$-like receptor activation (Krizaj et al., 1998) in amphibians and turtles, as does cone-cone coupling in turtles (Copenhagen and Green, 1987). In contrast, rod-cone coupling is thought to decrease with dopamine $\mathrm{D}_{2}$-like receptor activation or light sensitization in goldfish (Wang and Mangel, 1996; Ribelayga et al., 2002). Such differences highlight the precise nature with which photoreceptor coupling is controlled in each species.

Light adaptation and dopamine $\mathrm{D}_{2} / \mathrm{D}_{4}$ receptor activation in 
photoreceptors are associated with a decrease in cytoplasmic cAMP (Cohen et al., 1992; Nir et al., 2002). Several adaptive effects are associated with cAMP changes, including photomechanical movements and calcium current regulation (Dearry and Burnside, 1985; Stella and Thoreson, 2000), although direct effects of cAMP on photoreceptor electrical coupling have not been reported.

In hybrid bass retina, gap junctions contain two closely related connexins (Cxs), Cx35, the ortholog of mammalian Cx36, and Cx34.7 (O'Brien et al., 1998). We hypothesized that the two bass connexins may confer different sensitivity to second messengers in the circuits within which they are expressed and provide a mechanism through which different regulatory capabilities are obtained. In this study, we have examined the regulation of these two connexins by cAMP and their distribution in the bass retina. The results reveal that both $\mathrm{Cx} 35$ and $\mathrm{Cx} 34.7$ may contribute to gap junctional coupling within the same cone photoreceptors. Furthermore, coupling through Cx35 gap junctions can be dynamically regulated by protein kinase A-dependent pathways.

\section{Materials and Methods}

Animals. Hybrid striped bass (Morone saxatilis $\times$ M. chrysops, $8-15 \mathrm{~cm}$ ) were obtained from Ekstrom Enterprises (Danevang, TX) and Danbury Fish Farms (Danbury, TX). Fish were maintained in circulating tanks in the laboratory on a $12 \mathrm{hr}$ light/dark cycle. Animals for these studies were killed in a dark-adapted state approximately $1 \mathrm{hr}$ before lights on. All animal procedures were performed within the guidelines of the Institutional Animal Welfare and Use Committee.

Cell lines. The full coding sequences of perch Cx35 and perch Cx34.7 were subcloned into pcDNA 3.1 Zeo (Invitrogen, Carlsbad, CA) from cDNA clones in pBluescript (O'Brien et al., 1998). For Cx35, an AluIXhoI fragment was cloned into EcoRV and XhoI sites of pcDNA. For Cx34.7, a HindIII-DraI fragment was cloned into HindIII and EcoRV sites of pcDNA. HeLa cells (clone CCL2; American Type Culture Collection, Manassas, VA) were transfected with $2 \mu \mathrm{g}$ of plasmid using Tfx20 reagent (Promega, Madison, WI) and grown under Zeocin (Invitrogen) selection $(100 \mu \mathrm{g} / \mathrm{ml})$ for 6 weeks. Resistant colonies were isolated and amplified under selection.

Clones were tested for connexin expression by immunostaining and reverse transcription (RT)-PCR (Fig. 1). Nontransfected HeLa cells always showed a low level of Neurobiotin (Vector Laboratories, Burlingame, CA) tracer coupling and a very low level of Lucifer yellow coupling, reflecting the expression of small amounts of endogenous connexin presumed to be Cx45 (Eckert et al., 1993). Transfection with Cx35 eliminated Lucifer yellow coupling and led to moderate increases in Neurobiotin tracer coupling similar to that seen with mouse Cx36 (Teubner et al., 2000). Transfection with Cx34.7 also eliminated Lucifer yellow coupling but did not lead to significant increases in Neurobiotin tracer coupling (see Fig. 2).

$R T$-PCR analysis of cell lines. Samples of each cell line were cultured in $75 \mathrm{~mm}^{2}$ flasks, rinsed twice with ice-cold PBS, and then scraped into $4 \mathrm{ml}$ of ice-cold PBS with a Teflon cell scraper. The cells were centrifuged, and total RNA was isolated from the cell pellets using Tri reagent (Sigma, St. Louis, $\mathrm{MO}$ ) following the manufacturer's protocol. RNA was stored as a $70 \%$ ethanolic solution at $-80^{\circ} \mathrm{C}$. For reverse transcription, $2 \mu \mathrm{g}$ of total RNA was precipitated from the ethanol solution by addition of sodium acetate. The dried pellets were dissolved in DEPC water and digested with RQ1 RNase-free DNaseI (Promega) for $1 \mathrm{hr}$ at $37^{\circ} \mathrm{C}$ to destroy contaminating genomic DNA. The remaining RNA was reverse-transcribed using a Superscript II first-strand cDNA synthesis kit (Invitrogen) and random hexamers to prime synthesis. One-half microliter aliquots of the $\mathrm{RT}$ reactions were used as templates for subsequent PCR.

Primers used for PCR amplification of Cx35 were GCACCAGTCGGCCAAGCAGAAG (forward) and TGCCCTCTTGTCGCCTCATTTTG (reverse), and those for Cx34.7 were GGCCTTCCCCATTTCCCACATC (forward) and CACCACCTGAATGATGTAAAAGCGG (reverse). PCR reactions were performed in a standard PCR reaction buffer (Roche Molecular
Biochemicals, Indianapolis, IN) with a $200 \mu \mathrm{M}$ concentration of each dNTP, a $0.5 \mu \mathrm{M}$ concentration of each primer, and $1 \mathrm{U}$ of Taq polymerase (Fermentas, Hanover, MD) in $20 \mu$ l. Cycling conditions were $92^{\circ} \mathrm{C}$ for $20 \mathrm{sec}, 60^{\circ} \mathrm{C}$ for $20 \mathrm{sec}$, and $72^{\circ} \mathrm{C}$ for $90 \mathrm{sec}$ for 33 cycles.

Tracer-coupling experiments. Transfected or control HeLa cells grown under Zeocin selection were plated onto glass coverslips. Experiments were performed within $2 \mathrm{~d}$ of plating because coupling was found to decline if cells were maintained longer in culture. Coverslips were perfused with oxygenated Ringer's medium (in mM: $150 \mathrm{NaCl}, 6.2 \mathrm{KCl}, 1.2$ $\mathrm{NaH}_{2} \mathrm{PO}_{4}, 1.2 \mathrm{MgSO}_{4}, 2.5 \mathrm{CaCl}_{2}, 10$ HEPES, and 10 glucose, $\left.\mathrm{pH} 7.4\right)$ at $22^{\circ} \mathrm{C}$. When used, drugs were added to the perfusate $10 \mathrm{~min}$ before the first injection. Agents used were the cAMP analogs Sp-8-cpt-cAMPS $(15 \mu \mathrm{M})$ and Rp-8-cpt-cAMPS (15 $\mu \mathrm{M}$; Alexis, San Diego, CA) and the gap junction inhibitor carbenoxolone (10 $\mu \mathrm{M}$; Sigma). None of the pharmacological treatments used caused changes in cellular morphology that could be detected.

Cells were impaled with thin-wall microelectrodes filled with $3.5 \%$ Neurobiotin and 1\% Lucifer yellow CH (Molecular Probes, Eugene, OR) in $50 \mathrm{~mm}$ phosphate buffer, $\mathrm{pH}$ 7.4. Electrodes were back-filled with $3 \mathrm{M}$ $\mathrm{LiCl}$. Cells were filled by iontophoresis for $2 \mathrm{~min}$ with $+1 \mathrm{nA}$ of current and fixed with $4 \%$ paraformaldehyde for $1 \mathrm{hr}$ after allowing time for tracer diffusion. Typically, several injections were made on a single coverslip, so the total diffusion time differed between injections. The time elapsed between injection and fixation was recorded for calculation of the diffusion coefficient.

Cells were visualized with streptavidin-Cy3 (Jackson ImmunoResearch, West Grove, PA) and imaged on a Zeiss (Thornwood, NY) LSM 410 confocal microscope using a fixed set of pinhole, contrast, and brightness settings and two different laser attenuation settings. To determine Neurobiotin concentration in each cell, pixel intensities in a fiveby-five pixel box centered on each cell were compared with a standard curve prepared from HeLa cells loaded with defined concentrations of Neurobiotin through patch pipettes. The distance between the center of each cell and the center of the injected cell was measured to determine diffusion distance. This parameter was normalized to the mean centerto-center spacing between individual cells, which was determined for each injection, to express distance in terms of cell diameters.

A linear 25-compartment diffusion model of the type described by Zimmerman and Rose (1985) was fit to the Neurobiotin concentration and diffusion distance data. In this model, each compartment refers to an individual cell, and the major parameter that governs diffusion is the diffusion coefficient through the gap junctions between compartments. The movement of tracer between adjacent compartments is described by a series of 25 differential equations that are solved for tracer flux given the total amount of diffusion time and a diffusion coefficient, $k$ (for examples of equations used, see supplemental material, available at www.jneurosci. org). Optimal fits were determined in the program MatLab by varying $k$ and another parameter, $b_{\mathrm{o}}$, the bolus injection rate. The parameter $b_{\mathrm{o}}$ represents the injection of tracer into the initial compartment for the $2 \mathrm{~min}$ of iontophoresis and is set to zero thereafter. This parameter is determined by the total amount of tracer in all the compartments and is insensitive to the diffusion rate between the cells (Mills and Massey, 1998). Data fits were evaluated by plotting cell intensities on a log intensity axis and determining the diffusion coefficient $k$ that best fit the rate of decline with distance and the delivery rate $b_{\mathrm{o}}$ that fit the overall tracer concentration. The effect of varying $b_{\mathrm{o}}$ was strictly to translate the position of the curve vertically on the logarithmic axis of tracer concentration and, again, had no effect on the rate of decline. The diffusion coefficient $k$ represents the proportion of tracer that diffuses from one compartment to another per second. All $k$ values $>0$ represent measurable tracer coupling.

In both previous work (Mills and Massey, 1998) and in this study, diffusion coefficients were stable across a wide range of sampled diffusion times, thus allowing a large number of injections to be compared from a given coverslip. In practice, diffusion times were limited to $\leq 25 \mathrm{~min}$ prevent "edge" effects, whereby tracer that diffused to the edge of a group of HeLa cells would create diffusion artifacts. In fact, no injections were found that labeled cells near the edge of a cluster.

Calculation of diffusion coefficients in this manner has the advantage that the coefficients are well determined, in that all adjacent pairs within 
the stained group provide an independent estimate of $k$. This produces a stable average for each injection, even with the probable large amount of variability in gap junctional area between any two adjacent cells. Double whole-cell patch clamp, although more sensitive, would require many pairs to produce a stable average.

Although injection is into a two-dimensional array of cells, we have used a linear model for computational simplicity. Both in previous studies and here, we found that the same data can be fit equally well with either the linear or a two-dimensional model, within the ability of the scatter of the data to constrain the model. The absolute values of the parameters naturally change, but a regular relationship exits. In this study, we also fit some data with a diffusion model based on a hexagonal array (see on-line supplemental material, available at www.jneurosci. org). Data fit with the linear model produced a lower estimate of $k$ than did data fit with the hexagonal model. However, the relationship between the estimates was constant across the full range of diffusion coefficients measured in this study and had a correlation coefficient of $r=0.99$.

In vitro phosphorylation. Portions of the cDNA coding for intracellular domains of perch Cx35 were cloned separately into bacterial expression vectors. For each construct, appropriate restriction sites were introduced into the connexin sequences by PCR using Pfu polymerase (Stratagene, La Jolla, CA), and the PCR products were subcloned into the expression vector. The C-terminal domain was cloned into pGexKG (Amersham Biosciences, Piscataway, NJ), resulting in a construct coding for a $33 \mathrm{kDa}$ fusion protein containing glutathione- $S$-transferase (GST) and amino acids 254-304 of Cx35. The fusion protein was expressed in Escherichia coli strain BL21 and purified from bacterial extracts by binding to glutathione-Sepharose 4B (Amersham Biosciences). The intracellular loop domain was cloned into pET15b (Novagen, Madison, WI) and coded for an $11 \mathrm{kDa}$ fusion protein containing a $6 \times$ His tag and amino acids 102-178 of Cx35. The fusion protein was expressed in E. coli strain BL21(DE3) and purified from extracts by binding to Nucleobond nickelnitrilotriacetic acid resin (Invitrogen).

For phosphorylation assays, $200 \mathrm{ng}$ of fusion protein bound to resin was incubated with $0.15 \mathrm{U}$ of protein kinase A (PKA) catalytic subunit (New England Biolabs, Beverly, MA) and $\left[\gamma^{32} \mathrm{P}\right] \mathrm{ATP}$ for $30 \mathrm{~min}$ at $37^{\circ} \mathrm{C}$ in a solution containing $50 \mathrm{~mm}$ Tris-Cl, $\mathrm{pH} 7.5,10 \mathrm{~mm} \mathrm{MgCl}, 0.2 \mathrm{~mm}$ ATP, $46 \mathrm{~mm} \mathrm{NaCl}, 1 \mathrm{~mm} \mathrm{KCl}, 4 \mathrm{~mm} \mathrm{Na}_{2} \mathrm{HPO}_{4}$, and 16\% glycerol. Phosphorylated proteins were resolved on SDS-PAGE gels and transferred to polyvinylidene difluoride (PVDF) membranes (Bio-Rad, Hercules, CA), followed by autoradiography of the membranes.

In situ hybridization. RNA probes were made from $\sim 270$ bp unique sequences in the intracellular loop (IL) regions of Cx34.7 and Cx35 mRNAs cloned into the pGem-T vector (Promega). Both sequences labeled unique transcripts in a Northern blot (O'Brien et al., 1998), but the Cx34.7IL probe also labeled the $28 \mathrm{~S}$ rRNA nonspecifically. To eliminate this problem, a 21 bp glycine-encoding repeat region was deleted from the probe construct through a loop-out mutagenesis protocol using a Quick-Change sitedirected mutagenesis system (Stratagene). Digoxygenin (DIG)-labeled RNA probes were made by in vitro transcription with SP6 (antisense strand) or T7 (sense strand) RNA polymerases in the presence of DIG-UTP (DIG RNA labeling kit; Roche Molecular Biochemicals).

Eye cups were fixed in $4 \%$ paraformaldehyde in DEPC-treated $0.1 \mathrm{M}$ sodium phosphate buffer $(\mathrm{PB}), \mathrm{pH} 7.4$, for $2 \mathrm{~d}$ at $4^{\circ} \mathrm{C}$ and the retinas were subsequently removed. Retinas were dehydrated through an ethanol series and embedded in paraffin. Sections $7 \mu \mathrm{m}$ thick were cut on a microtome and dried overnight at $40^{\circ} \mathrm{C}$. Dried sections were deparaffinized, digested with $40 \mu \mathrm{g} / \mathrm{ml}$ proteinase $\mathrm{K}$, fixed briefly with $4 \%$ paraformaldehyde and PBS, treated with $0.25 \%$ acetic anhydride, washed with $5 \times$ SSC, and incubated in the hybridization buffer (40\% deionized formamide, $10 \%$ dextran sulfate, $1 \times$ Denhardt's solution, $4 \times$ SSC, $10 \mathrm{~mm}$ DTT, and $1 \mathrm{mg} / \mathrm{ml}$ denatured and sheared salmon sperm DNA) for 2-3 $\mathrm{hr}$ at $50^{\circ} \mathrm{C}$. Probes were applied at a concentration of $500 \mathrm{ng} / \mathrm{ml}$ in hybridization buffer overnight at $50^{\circ} \mathrm{C}$. After stringency washes at $50^{\circ} \mathrm{C}$, slides were treated with $2 \% \mathrm{H}_{2} \mathrm{O}_{2}$ and $\mathrm{PBS}$ for 10 min to quench endogenous peroxidase activity, blocked with TNB blocking buffer (2\% TNB blocking agent in PBS; Tyramide Signal Amplification florescence system; PerkinElmer Life Sciences, Boston, MA) for $30 \mathrm{~min}$ and labeled with anti-DIG-HRP (1:200; Roche Molecular Biochemicals) in TNB blocking
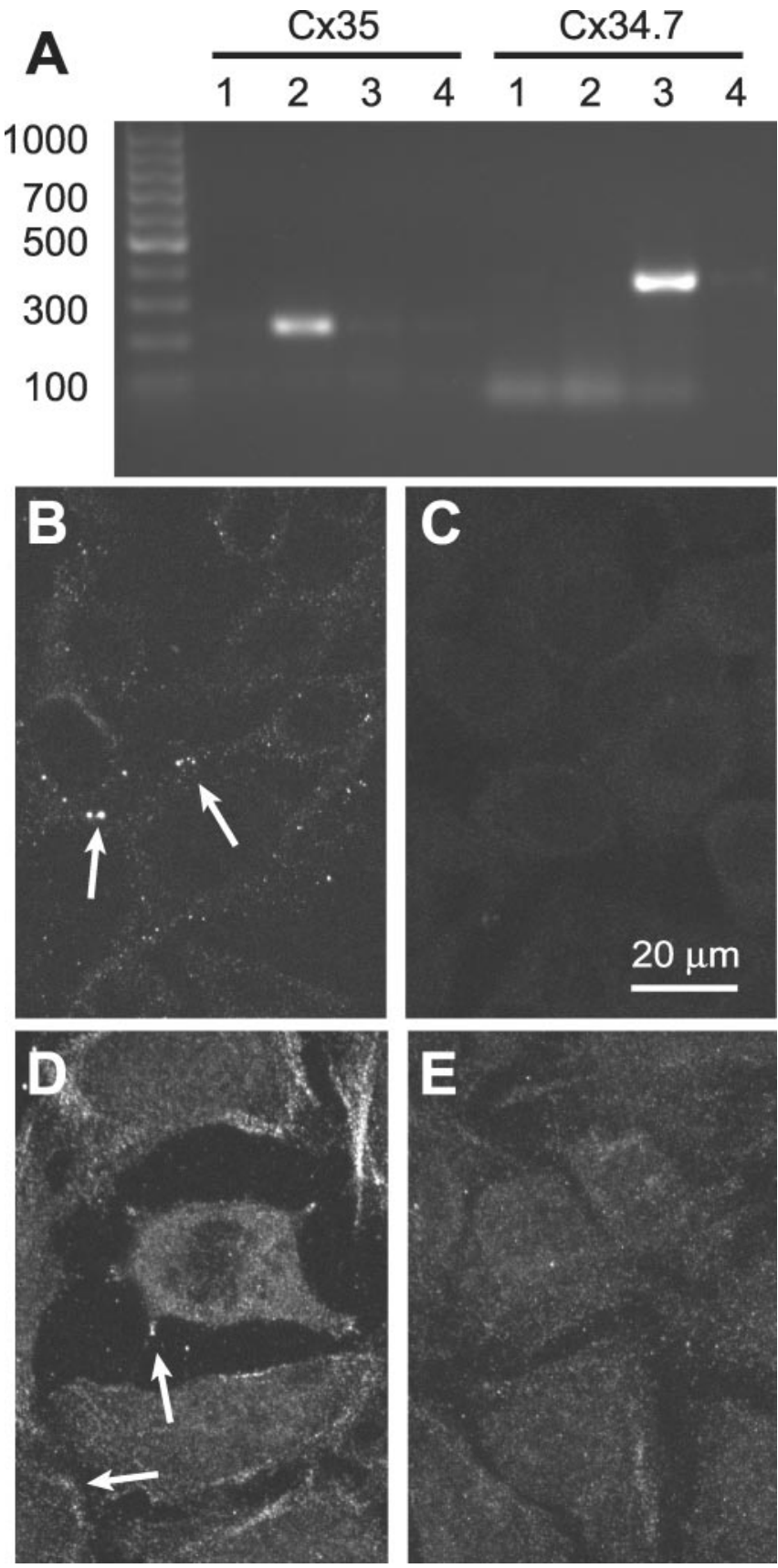

Figure 1. Expression of transfected connexins in HeLa cells. A, RT-PCR screening for expression of $\mathrm{C} \times 35$ and $\mathrm{C} \times 34.7$ in total RNA isolated from HeLa cell lines. For each primer set, lane 1 represents RNA from nontransfected HeLa cells; lane 2, RNA from Cx35-transfected cells; lane 3, RNA from Cx34.7-transfected cells; and lane 4, no template RT reaction control. Transfected HeLa cells showed specific expression of the connexin transfected. B, C, Immunostaining for CX35 in Cx35-transfected cells ( $B$ ) revealed punctate staining at cell- cell contacts (arrows) that was not present in nontransfected cells ( $C$. Scale bar in $C$ is the same for $B-E$. D, E, Immunostaining for $C \times 34.7$ in Cx34.7-transfected cells $(D)$ revealed punctate staining at cell contacts (arrows) and diffuse staining around the cell periphery. Nontransfected cells $(E)$ lacked the diffuse staining and staining at contacts and showed only occasional speckles more consistent with nonspecific background.

buffer overnight at $4^{\circ} \mathrm{C}$. After washing with PBS and $0.3 \%$ Triton X-100, the sections were incubated with $\mathrm{Cy} 3$ tyramide for 2-10 min. Processed tissue was mounted on microscope slides using Vectashield (Vector Laboratories) and viewed with an Olympus Optical (Tokyo, Japan) Vanox AHBT3 fluorescence microscope as well as a Zeiss LSM410 confocal microscope. 

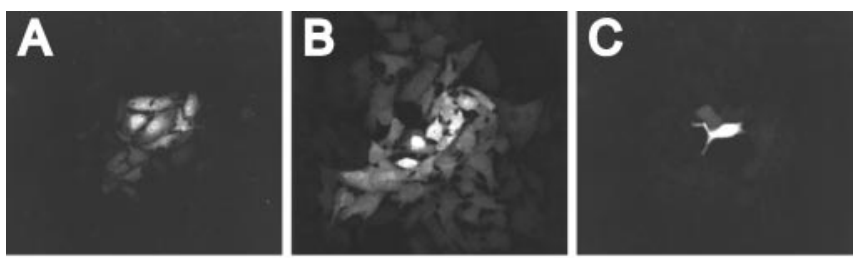

D

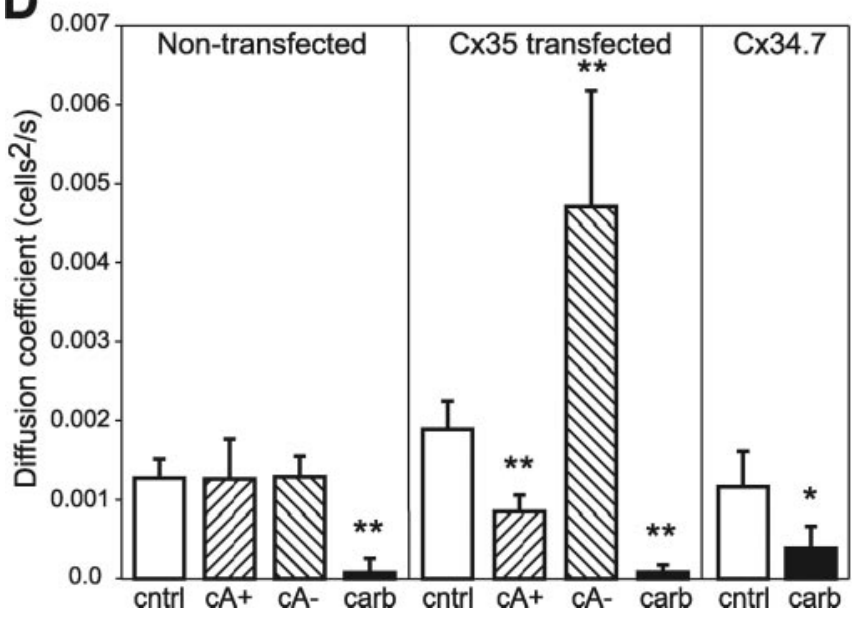

Figure 2. Cx35-mediated tracer coupling is regulated by protein kinase A. A, Neurobiotin injected into untransfected HeLa cells (control) spreads to a small number of cells through gap junctions composed of an endogenous connexin. $B$, Neurobiotin injection into cells stably transfected with Cx35 diffuses into a larger number of cells (for quantitative measure, see D). C, Bath application of the membrane-permeant CAMP analog Sp-8-cpt-cAMPS (8 $\mu \mathrm{M})$ to Cx35transfected HeLa cells 15 min before injection results in restriction of tracer diffusion to a few cells. D, Diffusion coefficients for Neurobiotin diffusion (for procedure and data analysis, see Materials and Methods) of HeLa cells either without transfection or stably transfected with CX35 or Cx34.7. In control (cntrl) HeLa cells, application of $15 \mu \mathrm{m}$ of the PKA activator Sp-8-cpt-cAMPS $(c A+)$ or $15 \mu \mathrm{m}$ of the PKA inhibitor Rp-8-cpt-cAMPS ( $C A-)$ caused no significant changes in diffusion coefficient (left plot, $p>0.05$ vs no drug; no drug, $n=20 ; c A+, n=10 ; c A-, n=$ 10). In Cx35-transfected cells, Sp-8-cpt-cAMPS caused a significant reduction in diffusion coefficient (center plot, $p<0.01$ vs no drug; no drug, $n=26 ; c A+, n=19$ ), whereas Rp-8-cptcAMPS caused a significant increase in diffusion coefficient ( $p<0.01$ vs no drug; $c A-, n=$ 10). Coupling in Cx34.7-transfected cells was not significantly different than in control HeLa cells (right plot, $p>0.05 ; n=20$ ). Coupling in all cell lines was significantly reduced to differing extent by $10 \mu \mathrm{m}$ carbenoxolone (carb; nontransfected, $n=5 ; C \times 35, n=9 ;(\mathrm{x} 34.7$, $n=6)$. ${ }^{*}$ Significant at the $p<0.05$ level; ${ }^{* *}$ significant different at the $p<0.01$ level.

Antibodies. Monoclonal antibodies were developed at Chemicon (Temecula, CA) against a maltose-binding protein fusion of the entire perch Cx35 intracellular loop (O'Brien et al., 1998) and screened using the His-tagged intracellular loop protein mentioned above. Clones 8F6 and 9D7 gave good results in immunohistochemistry. Clone 8F6 (available as Chemicon MAB3045) was used throughout this study. The antibody has not been epitope-mapped.

Polyclonal antibodies against Cx34.7 were raised in rabbits (Bethyl Laboratories, Montgomery, TX). Antibodies were directed against an intracellular loop peptide of sequence DYGGRDGARKLRNICG linked to KLH and were affinity-purified with the same peptide.

Monoclonal antibodies against SV2 were obtained from the Developmental Studies Hybridoma Bank (University of Iowa, Iowa City, IA). The monoclonal antibody against zebrafish cone membranes, FRet43 (Larison and Bremiller, 1990), was obtained from the University of Oregon Zebrafish International Resource Center (Eugene, OR). This antibody is distributed under the description ZPR1. The rabbit anti-protein kinase $\mathrm{C}$ $\alpha(\mathrm{PKC} \alpha)$ was obtained from Santa Cruz Biotechnologies (Santa Cruz, CA). All secondary antibodies were obtained from Jackson ImmunoResearch except for Alexa fluor 488 anti-mouse IgG, which was from Molecular Probes. Secondary antibodies were multiple-labeling grade preparations when available.

Western blots. Crude homogenates of hybrid bass brain, retina, and

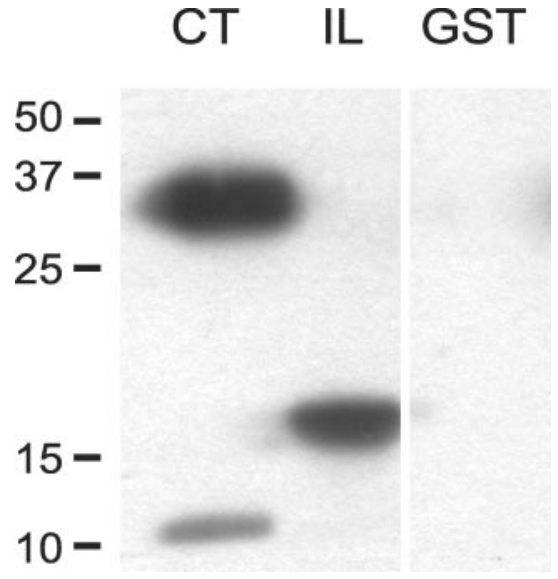

Figure 3. Cx35 cytoplasmic domains can be phosphorylated by PKA. Autoradiogram shows in vitro phosphorylation of bacterially expressed fusion proteins containing $\mathrm{C} \times 35$ intracellular domains. The C terminus of $\mathrm{C} \times 35$ (CT) was fused to glutathione-S-transferase, and the IL domain was fused to a $6 \times$ His tag. Both domains of $\mathrm{C} \times 35$ were phosphorylated by the PKA catalytic subunit, whereas GST alone was not.

liver tissue were prepared in Laemmli sample buffer without reducing agents and assayed for protein content with the BCA protein assay (Pierce, Rockford, IL). Samples were adjusted to $4 \mathrm{mg}$ of protein $/ \mathrm{ml}$, and $\beta$-mercaptoethanol was added to $2.5 \%$ before heating samples to $70^{\circ} \mathrm{C}$ and loading the gels. Eighty microgram aliquots of protein were separated by SDS-PAGE and transferred onto PVDF membranes. Similar procedures were followed for lysates of bacteria expressing GST fusion proteins of the $\mathrm{Cx} 35$ or $\mathrm{Cx} 34.7$ intracellular loop. Bacterial extracts were loaded at $5 \mu \mathrm{g} /$ lane. After Western transfer, membranes were blocked with $4 \%$ nonfat dry milk in TBST $(500 \mathrm{~mm} \mathrm{NaCl}, 3 \mathrm{~mm} \mathrm{KCl}, 25 \mathrm{~mm}$ Tris-Cl, pH 7.4, and $0.05 \%$ Tween 20) and probed with either mouse anti-Cx35 (dilution, 1:500) or rabbit anti-Cx34.7IL (dilution, 1:4000) plus $2 \%$ nonfat dry milk in TBST. The secondary antibody was coupled to horseradish peroxidase (dilution, 1:5000). Bands were detected by enhanced chemiluminescence (Pierce).

Immunocytochemistry. Hybrid bass eye cups were collected from darkadapted, subjective morning fish and fixed in $4 \%$ paraformaldehyde in $0.1 \mathrm{M}$ PB for $30 \mathrm{~min}$. Eye cups were washed in $0.1 \mathrm{M}$ PB and embedded in $4 \%$ low-melt agarose (Sigma), and $40-50 \mu \mathrm{m}$ sections were cut on a Vibratome. Sections were preincubated with $3 \%$ normal goat serum in PBST (137 mm NaCl, $2.7 \mathrm{~mm} \mathrm{KCl,} 10 \mathrm{~mm} \mathrm{Na}_{2} \mathrm{HPO}_{4}, 1.7 \mathrm{~mm} \mathrm{KH}_{2} \mathrm{PO}_{4}$, $0.5 \%$ Triton X-100, and $0.1 \%$ sodium azide) for $2 \mathrm{hr}$ to block nonspecific labeling. Sections were then incubated in primary antibodies as described below. For experiments involving two monoclonal antibodies (e.g., Cx35 and SV2), we used a sequential labeling technique. Sections were first incubated overnight at $4^{\circ} \mathrm{C}$ with mouse anti-Cx35 (dilution, 1:500) in PBST plus $1 \%$ goat serum, washed, and then probed with Alexa 488 anti-mouse IgG (dilution, 1:200) in PBST alone. Subsequently, sections were incubated in rabbit anti-Cx34.7IL (dilution, 1:500) and mouse antiSV2 (dilution, 1:2000) in the same solution of $1 \%$ goat serum plus PBST overnight at $4^{\circ} \mathrm{C}$. After washing, we applied Cy3 conjugated to goat antimouse (dilution, 1:200) and Cy5 conjugated to goat anti-rabbit (dilution, 1:200). Processed tissue was mounted on microscope slides using Vectashield (Vector Laboratories) and viewed with a Zeiss LSM 410 confocal microscope.

Similar procedures were followed for HeLa cells grown on $14 \mathrm{~mm}$ coverslips, except that some cells were fixed by immersion for $5 \mathrm{~min}$ in acetone at $-20^{\circ} \mathrm{C}$. Primary antibodies were used at 1:500 for mouse antiCx35 and 1:1000 for rabbit anti-Cx34.7IL. Cy3-labeled secondary antibodies were used for all experiments.

\section{Results}

Cx35 gap junctions are regulated by

cAMP-dependent pathways

In many retinal circuits, cAMP-dependent pathways regulate gap junctional coupling. To test the regulation by cAMP-mediated 
pathways of gap junctions formed by the retinal connexins $\mathrm{Cx} 35$ and $\mathrm{Cx} 34.7$, we generated stably transfected HeLa cell lines that express these connexins. Expression of the connexins was confirmed by RTPCR analysis of total RNA extracted from the cell lines (Fig. 1A). Transcription of the transfected connexin was limited to the cell lines in which it was transfected. To further evaluate expression of the transfected connexins, we performed immunostaining of the cultures (Fig. $1 B-E$; for characterization of the antibodies used, see Fig. 5). Cx35 was expressed in numerous very small gap junctions (Fig. $1 B$, arrows), that were not present in untransfected HeLa cells (Fig. 1C). Readily apparent plaques were observed at an abundance of $1.9 \pm 0.3$ plaques per cell $(n=4$ images, 65 cells). For Cx34.7 HeLa cells, there were relatively fewer apparent plaques (Fig. $1 D$, arrows), $0.8 \pm 0.2$ plaques per cell $(n=5$ images, 34 cells) and a substantial amount of poorly organized immunostaining around the periphery of the cells. For the Cx34.7 antibody, substantial background immunostaining was also present in untransfected HeLa cells (Fig. 1E). From these data, it is apparent that both connexins were translated into protein and localized to cell-cell contacts, although Cx35 showed more typical organization into junctional plaques.

Functional properties of the gap junctions were tested by injection of Neurobiotin and Lucifer yellow into monolayers of cells and analysis of tracer transfer by fluorescence microscopy after fixation and labeling with Cy3-streptavidin. In control HeLa cells, a small amount of Neurobiotin tracer transfer was generally observed (Fig. $2 \mathrm{~A}$ ) but little Lucifer yellow transfer (results not shown). The diffusion coefficient for Neurobiotin measured in control cells was $1.27 \times 10^{-3} \pm$ $2.47 \times 10^{-4}$ cells $^{2} / \mathrm{sec}(n=29)$. HeLa cells stably expressing Cx35 transferred significantly more Neurobiotin (diffusion coefficient, $1.89 \times 10^{-3} \pm 3.57 \times 10^{-4}$ cells $^{2} / \mathrm{sec}$; $n=26 ; t=1.96 ; p<0.05$ ) (Fig. $2 B$ ) but never showed Lucifer yellow permeability.

In Cx35-transfected cells, application of the membrane-permeant cAMP analog Sp-8-cpt-cAMPS $(15 \mu \mathrm{M})$ reduced coupling by $55 \%\left(8.49 \times 10^{-4} \pm 2.14 \times 10^{-4}\right.$ cells ${ }^{2} / \mathrm{sec} ; n=19 ; t=-3.30 ; p<0.01$ vs control) (Fig. 2C). Sp-8-cpt-cAMPS is a potent and selective activator of cAMP-dependent protein kinase (PKA). The Rp isomer of this compound selectively inhibits PKA. Figure $2 D$ shows that application of Rp-8-cpt-cAMPS to Cx35transfected cells increased the diffusion coefficient $150 \%$ over control conditions $\left(4.71 \times 10^{-3} \pm 1.47 \times 10^{-3}\right.$ cells $^{2} / \mathrm{sec} ; n=$ $10 ; t=3.41 ; p<0.01$ vs control). Coupling in Cx35-transfected cells was also inhibited by the general gap junction inhibitor carconfocal stack.
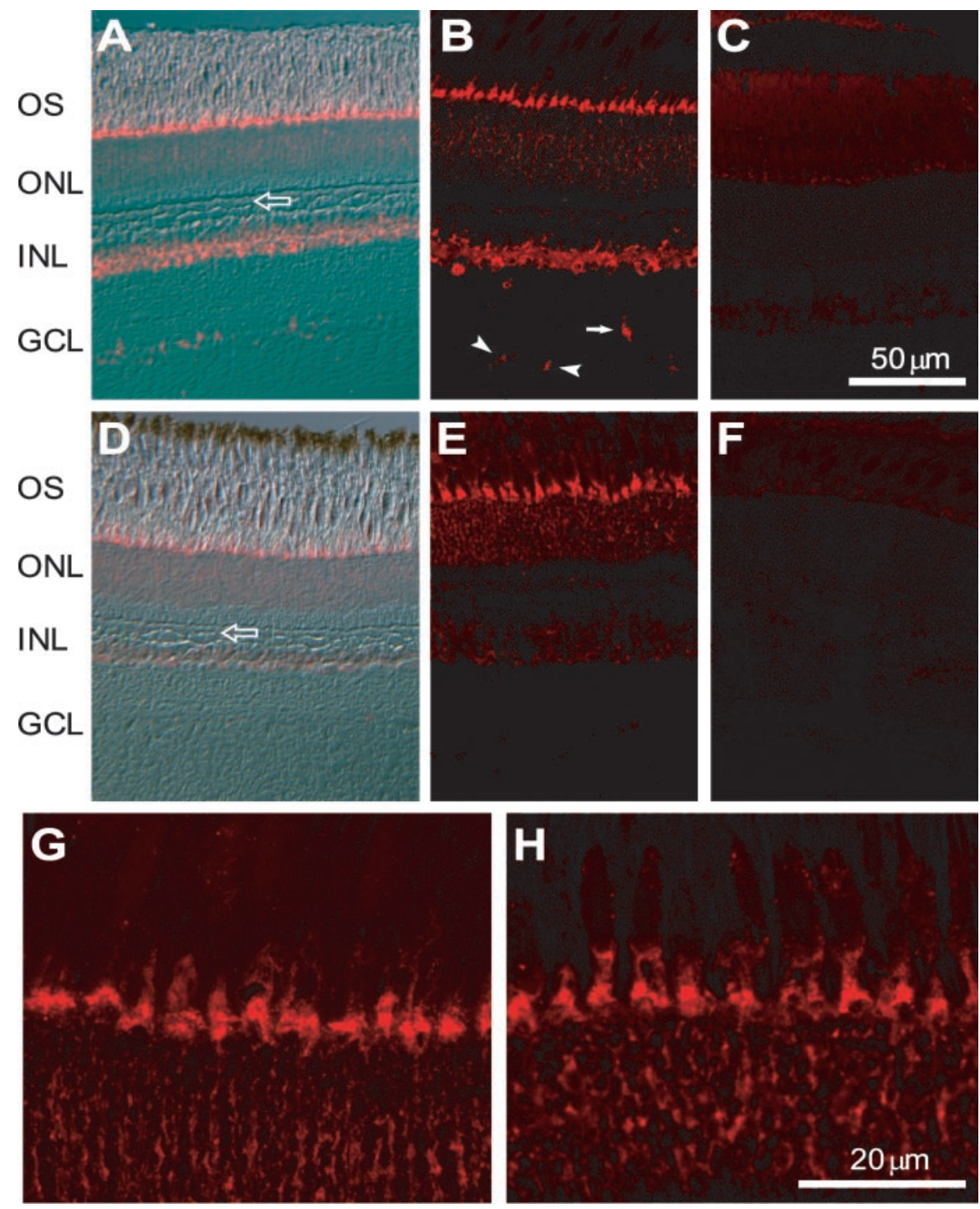

Figure 4. $\quad$ (x35 and $C \times 34.7 \mathrm{mRNA}$ shave different but overlapping distributions in the retina. $A$, In situ hybridization with a $C \times 35$ intracellular loop antisense probe labeled three regions of the bass retina. Hybridization signal is visualized by Cy 3 fluorescence in red overlaid on the Nomarski image of the section. Labeling is most prominent in the photoreceptor layer between the outer segments (OS) and ONL, within the INL, and in the GCL. Hybridization signal in the INL is restricted to the lower half, and the large, block-like horizontal cells (open arrow) are clearly not labeled. Scale bar in ( applies to A-F. B, Confocal micrograph of a similar section showing faint labeling throughout the ONL. Cells within the GCL fall into two groups: scarce cells with large somata (filled arrow) presumably representing some types of ganglion cells and more common cells with small somata (arrowheads) that are more likely displaced amacrine cells. Image is a $4 \mu \mathrm{m}$ confocal stack. C, Sections probed with the $\mathrm{C} \times 35$ sense strand show no labeling. Image is a $4 \mu \mathrm{m}$ confocal stack. D, In situ hybridization with a $(x 34.7$ intracellular loop antisense probe (for details, see Materials and Methods) labels only one band in the photoreceptor layer strongly. Faint labeling was detected in the INL, but horizontal cells were again without label (open arrow). E, Confocal micrograph of a $(x 34.7$ antisense hybridization showing more clearly the labeling in the photoreceptor layer and very faint labeling in the INL. Image is a $4 \mu \mathrm{m}$ confocal stack. $F, C \times 34.7$ sense strand probe shows no labeling. Image is a $4 \mu \mathrm{m}$ confocal stack. $G$, Confocal micrograph of the photoreceptor layer of $\mathrm{Cx} 35$ labeled section. Prominent areas of labeling are in the myoid regions of cone photoreceptors, which have large oval ellipsoids immediately above the labeled region. Image is a $4 \mu \mathrm{m}$ confocal stack. $H$, Confocal micrograph of the photoreceptor layer of a Cx34.7-labeled section. Prominent labeling is in the same region of cone photoreceptors, as is Cx35 labeling. Image is a $4 \mu \mathrm{m}$

benoxolone $\left(7.8 \times 10^{-5} \pm 3.1 \times 10^{-5}\right.$ cells $^{2} / \mathrm{sec} ; n=9 ; t=$ $-5.04 ; p<0.01$ vs control). Coupling in control HeLa cells was insensitive to activators and inhibitors of PKA but was inhibited by carbenoxolone (Fig. 2D). The diffusion coefficient in Cx35transfected cells thus varied over greater than a fivefold range under the influence of PKA activity.

Cx34.7-transfected cells, like Cx35-transfected cells, showed 
Neurobiotin tracer coupling but not Lucifer yellow dye coupling (results not shown). However, Neurobiotin tracer coupling in Cx34.7-transfected cells was not different than in control HeLa cells $\left(1.16 \times 10^{-3} \pm 4.54 \times 10^{-4}\right.$ cells $^{2} / \mathrm{sec} ; n=20 ; t=-0.50$; $p>0.05$ ) (Fig. $2 D$ ), although inhibition by carbenoxolone was somewhat less effective $\left(3.83 \times 10^{-4} \pm 2.59 \times 10^{-4}\right.$ cells $^{2} / \mathrm{sec}$; $n=6 ; t=-2.79 ; p<0.05 \mathrm{vs}$ control). Several independent stably transfected cell lines were tested with similar results. Because of the low level of functional coupling in Cx34.7-transfected cells, it was not possible to study the effects of pharmacological agents on coupling in these cell lines.

\section{Cx35 cytoplasmic domains are phosphorylated by PKA}

The experiments above indicated that pathways involving protein kinase A regulated coupling through Cx35 gap junctions. However, it could not be determined whether regulation depends on modification of channels in the gap junction or on recruitment and removal of channels to and from the gap junction. To characterize further the regulation of $\mathrm{Cx} 35$ gap junction channels by PKA, we examined the ability of PKA to phosphorylate the connexin cytoplasmic domains. Both major cytoplasmic domains were expressed as fusion proteins in E. coli and purified. The C-terminal tail was fused to GST, and the intracellular loop domain was fused to a $6 \times$ His tag. Figure 3 shows in vitro phosphorylation assays in which the PKA catalytic subunit was used to phosphorylate the purified fusion proteins. Both intracellular loop and C-terminal domains of Cx35 were phosphorylated by PKA, whereas GST alone was not phosphorylated. This shows that PKA can phosphorylate the connexins directly at a minimum of two sites, one in each of the intracellular loop and C-terminal domains. Thus, the pathways through which PKA activity reduces Cx35 coupling may involve direct phosphorylation of the connexin.

\section{Expression of $\mathrm{Cx} 35$ and $\mathrm{Cx} 34.7$ in retinal neurons is partially overlapping}

In previous studies, we found that both $\mathrm{Cx} 35$ and $\mathrm{Cx} 34.7$ were expressed in the retina (O'Brien et al., 1998). We wished to determine whether the same or different cells in the retina expressed these connexins. To study this, we performed in situ hybridizations with RNA probes derived from the intracellular loop domains of the two connexins. The two connexins differ most in this region, and we have previously shown that probes derived from this domain label different transcripts in a Northern blot (O'Brien et al., 1998). The labeling pattern of the Cx35 antisense probe is shown in Figure 4, $A$ and $B$. A strong band of hybridization was seen at photoreceptor inner segments, with weak labeling throughout the outer nuclear layer (ONL). Many cells in the inner half of the inner nuclear layer (INL) were labeled. These correspond to the positions of amacrine cell somata and perhaps some bipolar cell somata. Note that the somata of horizontal cells, visible in the Nomarski overlay of Figure $4 A$ (open arrow), were not labeled. A few cells in the ganglion cell layer (GCL) were also labeled. These included cells with small somata that probably correspond to displaced amacrine cells (Fig. $4 B$, arrowheads) and a much smaller number of cells with large somata that may correspond to some types of ganglion cells (Fig. 4B, arrow). Most ganglion cells were not labeled. The sense strand probe showed no labeling (Fig. 4C). In contrast to $\mathrm{Cx} 35$, the $\mathrm{Cx} 34.7$ antisense probe labeled only the photoreceptor inner segments strongly (Fig. 4D,E). Very weak labeling was present in the inner half of the INL, with a distribution similar to that of $\mathrm{Cx} 35 \mathrm{mRNA}$. Once again, no labeling was detected with the sense strand probe (Fig. $4 F$ ).
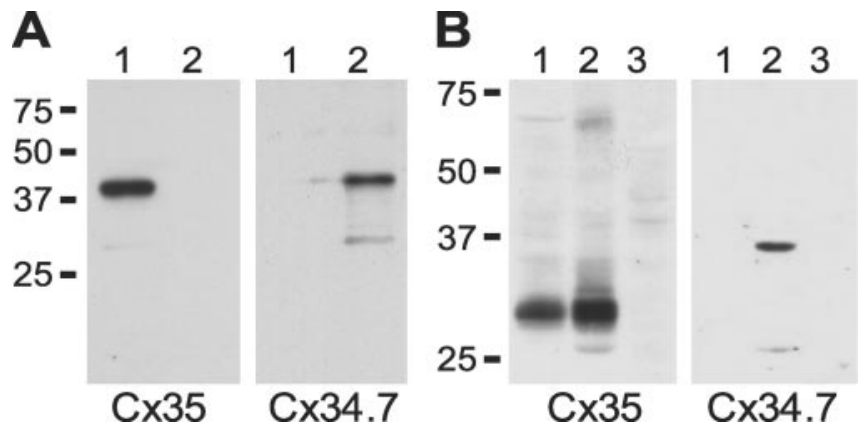

Figure 5. Antibodies to $C \times 35$ and $(x 34.7$ label connexins selectively. $A$, Western blot analysis of crude lysates of bacteria expressing a GST-Cx35 intracellular loop fusion protein (lanes 1, left and right panels) or a GST-Cx34.7 intracellular loop fusion protein (lanes 2, left and right panels). Both (x35 monoclonal (left panel) and (x34.7 polyclonal (right panel) antibodies are specific. $B$, Western blot analysis of hybrid bass tissues using anti-CX35 monoclonal (left) and anti-CX34.7 polyclonal (right) antibodies. Each lane contains $80 \mu \mathrm{g}$ of crude protein from hybrid bass brain (lanes 1), retina (lanes 2), or liver (lanes 3 ). The (x35 antibody recognizes a complex of bands at $30-33 \mathrm{kDa}$ in brain and retina. A higher-mass band at $\sim 65 \mathrm{kDa}$ may represent $\mathrm{Cx} 35$ dimers. The $C x 34.7$ antibody recognizes a single band of $\sim 36 \mathrm{kDa}$ only in retina.

Because both Cx35 and Cx34.7 transcripts were present in the photoreceptor layer, we wished to determine whether rods, cones, or both expressed the connexins. Closer examination of the photoreceptor layer (Fig. 4G,H) showed that the strongest labeling for both $\mathrm{Cx} 35$ and $\mathrm{Cx} 34.7$ occurred in the cone inner segments. In this species, the cones are easily identified by their large oval ellipsoid, which can be seen to be continuous with the hybridization signal by virtue of the background signal developed in that region. Weak signal throughout the OPL could not be ascribed specifically to rods or cones, so we could not determine whether rods express either Cx35 or Cx34.7. Coexpression of these connexins in the same neurons raised the question of whether the connexins occurred in the same or different gap junctions.

\section{Cx35 and Cx34.7 occur in different gap junctions}

To study the distribution of Cx35 and Cx34.7 in the retina, we made use of antibodies against the two connexins. Western blot analysis of crude tissue homogenates and lysates of bacteria expressing fusion proteins is shown in Figure 5. In lysates of bacteria expressing connexin fusion proteins, monoclonal anti-Cx35 recognized only the $\mathrm{Cx} 35$ fusion protein in lane 1 (Fig. $5 \mathrm{~A}$, left panel) and not the $\mathrm{Cx} 34.7$ fusion protein in lane 2. The polyclonal antiCx34.7 recognized only the Cx34.7 fusion protein (Fig. 5A, right panel). In tissue lysates, anti-Cx35 recognized a complex of two to three bands at apparent $M_{\mathrm{r}}$ of $31-33 \mathrm{kDa}$ in both brain (lane 1) and retina (lane 2) homogenates, whereas anti-Cx34.7 recognized a single band at an apparent $M_{\mathrm{r}}$ of $36 \mathrm{kDa}$ only in the retina sample. Although Cx35 appears to run smaller than its predicted molecular mass, it is not unusual for connexins to have anomalous apparent $M_{\mathrm{r}}$ in SDS-PAGE. For Cx35, this migration pattern has been a consistent result for our gel system with several different species and several different antibodies (cf. Pereda et al., 2003; our unpublished results). It is likely that a secondary structure in the denatured protein contributes to this anomalous migration pattern.

To study the distribution of the two connexins, we first examined the distribution of $\mathrm{Cx} 35$ immunoreactivity relative to wellestablished markers of retinal neurons. In Figure 6, an antibody to the synaptic vesicle protein SV2 was used to label synaptic vesicles in both inner and outer plexiform layers, and an antibody 
to $\mathrm{PKC} \alpha$ was used to label the roddominant Mb1 bipolar cells (cf. Suzuki and Kaneko, 1990; Yazulla and Studholme, 2001). Cx35 (green) was abundant in both the inner and outer plexiform layers, with no labeling detected outside of these layers. In the outer plexiform layer (Fig. 6B), Cx35 plaques were numerous below the photoreceptor terminals, with some minute plaques occasionally seen among the terminals. Very little was coincident with the Mb1 bipolar cell processes, suggesting that most $\mathrm{Cx} 35$ plaques must be among processes of other bipolar cells, photoreceptor telodendria, or both. Cx35 gap junctions among horizontal cell processes were ruled out because of the lack of Cx35 mRNA in any horizontal cells.

In the inner plexiform layer, Cx35 plaques were abundant in both the $\mathrm{ON}$ and OFF sublaminas (Fig. 6C), consistent with the in situ hybridization data indicating that many amacrine cell types express this connexin. The gap junctions varied in size from very large plaques up to $8 \times$ $3 \mu \mathrm{m}$ to small plaques $<0.5 \mu \mathrm{m}$ in diameter. The telodendria of Mb1 bipolar cell axon terminals were found to contain very small Cx35 gap junctions (arrows) wherever these processes met. Thus, it is clear that some bipolar cells do express Cx35.

In contrast to the widespread staining for $\mathrm{Cx} 35, \mathrm{Cx} 34.7$ was detected only in the outer plexiform layer (Fig. 7A). This result is consistent with the in situ hybridization data showing that the major Cx34.7 mRNA signal was present in photoreceptors. When photoreceptor terminals were labeled with SV2, we found that Cx34.7 immunostaining was detected almost exclusively beneath cone pedicles (Fig. 7B). In many cases, Cx34.7 immunostaining was found deep within the basal invagination of the cone pedicle, close to areas of synaptic contacts. Cx35 immunostaining, on the other hand, was generally found $1-2 \mu \mathrm{m}$ below the zone of synaptic contacts, although some plaques were found within the basal invagination. In no case were $\mathrm{Cx} 35$ and $\mathrm{Cx} 34.7$ found to colocalize (Fig. $7 C-E$ ), indicating that these connexins form different gap junctions. Because of the complexity of the synaptic layer beneath cone terminals and the potential for Cx35 expression in some bipolar cells, it was important to delineate further the origin of the connexin immunolabeling in the outer plexiform layer.

\section{Cone telodendria participate in gap junctions made by $\mathrm{Cx} 35$}

To identify telodendria of cone photoreceptors, we used an antibody (FRet43) that specifically labels the membranes of double cones (Larison and Bremiller, 1990). This antibody labeled a majority of hybrid bass cones, leaving a small population of single cones ( $<10 \%$ of cones) unlabeled (results not shown). Figure $8 \mathrm{~A}$ shows that cone terminals extend several thin telodendria that contact the bases of other cones or contact other telodendria at terminal swellings within the OPL. Cx35 immunoreactivity colocalized extensively with the telodendrial matrix at linear plaques (triple arrowheads). Furthermore, swellings indicative of tip-totip contacts of telodendria invariably contained a Cx35 plaque (arrows). Most Cx34.7 immunoreactivity was superimposed on cone terminals and was not readily traceable to specific telodendria in whole-mount views. However, the few $\mathrm{Cx} 34.7$ plaques found away from the labeled terminals did coincide with labeled telodendria.

Vertical sections of bass retina labeled for FRet43 and both connexins revealed the extensive complex of basal processes beneath each cone terminal and telodendria connecting cones (Fig. $8 B)$. Cx35 plaques were frequently associated with these processes, indicative of gap junctions between telodendria. Other Cx35 plaques in this region may also represent bipolar cell gap junctions. In a few cases, cone telodendria could be seen to project into the invagination of a cone terminal (Fig. $8 \mathrm{C}$, arrow), and a Cx34.7 plaque was sometimes found at the projected tip of the process. A direct connection between the telodendria and Cx34.7 plaques could not be detected in these views.

The association of $\mathrm{Cx} 34.7$ with cone telodendria was examined more closely in double-labeled material that provided more sensitive detection of the two fluorochromes. Confocal stacks of oblique sections of retina showed more clearly that telodendria frequently project from one cone into the central invagination of an adjacent cone (Fig. 8D). In such specimens, a cluster of $\mathrm{Cx} 34.7$ plaques was generally observed in the vicinity of the contacts of these telodendria with the cone pedicle. However, direct association of Cx34.7 with the telodendria again was not apparent. To examine this relationship, we examined single confocal sections and stacks of $\leq 1 \mu \mathrm{m}$ in thickness. Well labeled vertical sections revealed an extremely dense complex of cone basal processes beneath each terminal (Fig. 8E). Very small Cx34.7 plaques were directly associated with these processes. Telodendria passing be- 

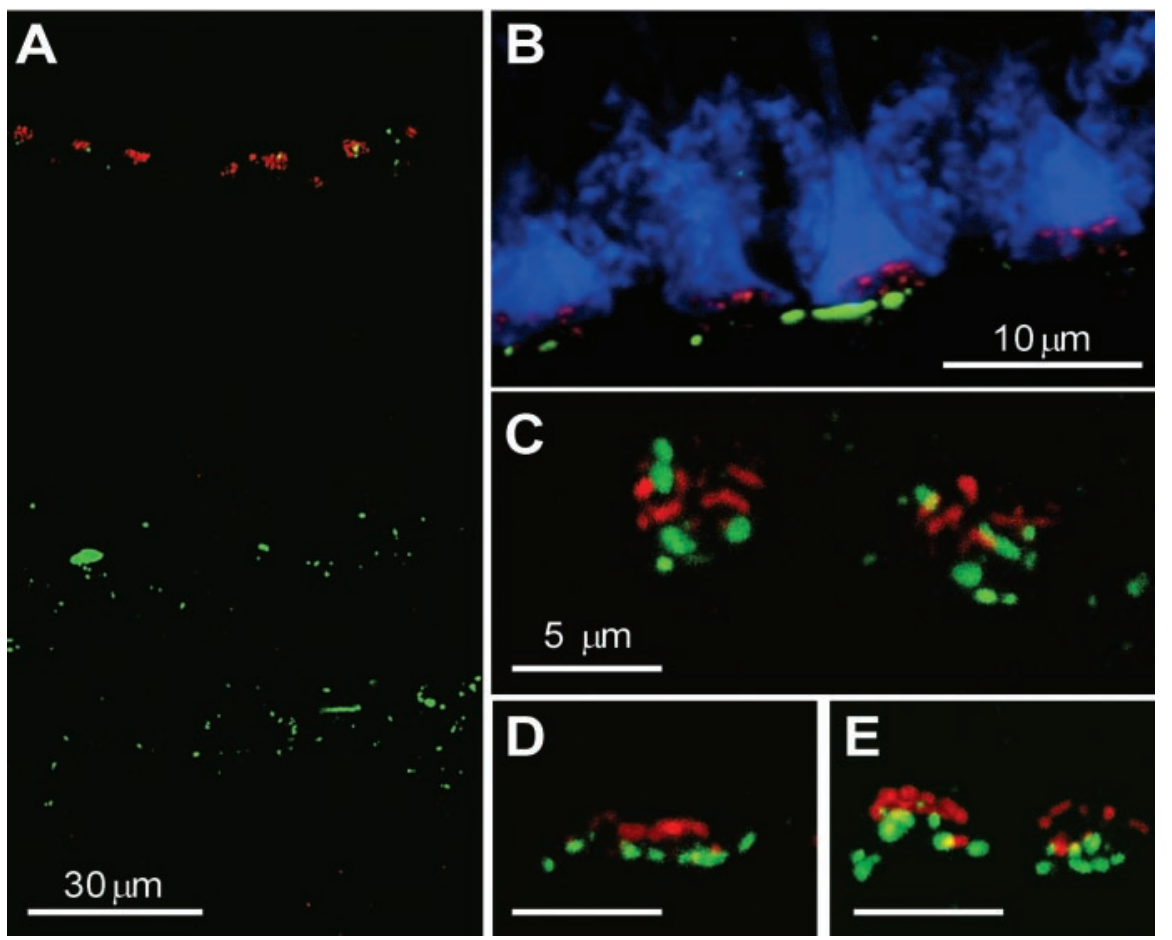

Figure 7. Cx34.7 protein is more limited in distribution. A, Double labeling for Cx34.7 (red) and Cx35 (green) shows distinctly different distributions of the two connexins. CX34.7 immunoreactivity is restricted to the outer plexiform layer in regularly spaced clusters. Cx35 is also present at this location. Image is a $5 \mu \mathrm{m}$ confocal stack. $B$, Labeling of the outer plexiform layer with SV2

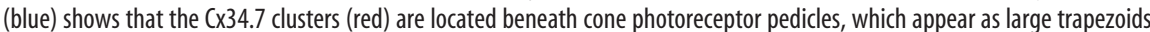
among the doughnut-shaped and much smaller rod terminals. (X35 immunolabeling (green) in the same vicinity is not restricted to the cone pedicles. Image is a $5 \mu \mathrm{m}$ confocal stack. $C-E$, Three views of $\mathrm{Cx} 34.7$ (red) and $C \times 35$ (green) immunoreactivity in the OPL. Although the connexins are in very close proximity, the two do not occur in the same plaques. The limited overlap visible in some images was attributable to stacking of confocal slices from different depths. C is a $3 \mu \mathrm{m}$ confocal stack of a whole-mount view; $D, 4 \mu \mathrm{m}$ confocal stack of a vertical section; $E, 6 \mu \mathrm{m}$ confocal stack of an oblique section. Scale bar in $C$ applies to $D, E$.

tween cones were often associated with larger $\mathrm{Cx} 34.7$ plaques (arrows) where they approached the terminal. However, immunostaining for FRet43 was notably absent where these larger plaques resided, leaving prominent gaps in the FRet43-labeled processes. This lack of association of Cx34.7 with Fret43 labeling could reflect an uneven distribution of the Fret43 antigen in the membrane surface, or it could suggest that processes of another cell type, such as a bipolar cell, make gap junctions with $\mathrm{Cx} 34.7$ in this area. The latter was considered unlikely because Cx34.7 mRNA was virtually absent from cells in the inner nuclear layer.

\section{Discussion}

\section{cAMP regulation of gap junctions}

cAMP has long been identified as a regulator of certain electrical synapses (Piccolino et al., 1984; Hampson et al., 1992; Rorig et al., 1995). This is the case in the AII amacrine cell homologous gap junctions, which have been found to contain connexin 36, the mammalian homolog of Cx35 (Feigenspan et al., 2001; Mills et al., 2001). In these cases, activation of $D_{1}$-type dopamine receptors reduces coupling. Dopamine $\mathrm{D}_{1}$ receptor activation is linked to enhanced adenylyl cyclase activity and elevation of cAMP. Lasater (1987) and DeVries and Schwartz (1989) found in horizontal cells that the action of cAMP on gap junctional conductance occurs through the activity of PKA. Thus, activation of $\mathrm{D}_{1}$ receptors results in elevation of cAMP, enhancing PKA activity and leading to reduction in coupling. The opposite effect of dopamine has been observed in rod-cone gap junctions (Krizaj et al.,
1998), where activation of $\mathrm{D}_{2}$-like receptors reduces cAMP and enhances gap junctional coupling.

In this study, we found that the steadystate diffusion coefficient of cells expressing Cx35 can be either increased or decreased by inhibition or activation, respectively, of PKA. These effects take place within a few minutes and provide a mechanism by which cells can quickly change their coupling state. The observation that $\mathrm{Cx} 35$ gap junctions are regulated dynamically by cAMP is consistent with the behavior of gap junctions containing homologs of this connexin in mammalian AII amacrine cells (Hampson et al., 1992; Mills and Massey, 1995). In both cases, pharmacological treatments that activate PKA reduced coupling.

Several mechanisms may account for the regulation we observed, including direct action of cAMP analogs on the connexin channels, modulation of gap junction channel activity by PKA phosphorylation of the connexins, modulation by a different downstream effector of cAMP signaling, or insertion or removal of channels. Although we could not distinguish between these mechanisms in our study, the in vitro experiments showed that $\mathrm{Cx} 35$ is phosphorylated at multiple sites by PKA. The direct phosphorylation pathway would be most consistent with the previous findings regarding the regulation of gap junction channel activity by cAMP.

The low level of functional coupling in cell lines expressing Cx34.7 makes it difficult to assess whether PKA regulates these gap junctions. Additional experiments will be required to determine whether these two gap junctional pathways are regulated separately.

\section{Which photoreceptors are involved?}

We have shown conclusively that cones express both Cx35 and Cx34.7, and Cx35 is associated with cone telodendria. The presence of gap junctions among cone telodendria has long been documented. Gap junctions have been observed between cone telodendria and cone pedicles or between telodendria in fish (Witkovsky et al., 1974, 1979; Scholes, 1975) and essentially all other types of vertebrates that have been studied (cf. Raviola and Gilula, 1973; Kolb and Jones, 1985). Thus, it is not surprising to find a connexin associated with cone telodendria.

It is somewhat surprising that we did not find clear evidence for the presence of $\mathrm{Cx} 35$ or $\mathrm{Cx} 34.7$ on rod photoreceptor terminals. Rod-cone gap junctions have been observed in most species, and indirect evidence exists for electrical coupling between rods and cones in fish (Ribelayga et al., 2002). It is logical to expect one of connexins 35 and 34.7 to mediate this coupling. However, telodendria of cones were not observed to penetrate distally among rod terminals, where gap junctions among rods have been seen, and the short telodendria of rods in fish have never been observed to project beneath cone terminals (Witkovsky et al., 1974, 1979), where Cx34.7 immunoreactivity was observed. Thus, neither Cx34.7 nor Cx35 is likely to be involved 
in rod gap junctions unless these gap junctions are removed in a circadian or adaptive process that we have not studied.

Recent reports in mammals indicate that Cx36 (the mammalian homolog of Cx35) mediates rod-cone coupling in the mouse (Deans et al., 2002). However, Lee et al. (2003) found that Cx36 is present at cone-cone gap junctions but only on the cone side of rod-cone gap junctions in guinea pig. Thus, although cone-cone gap junctions seem consistently to contain $\mathrm{Cx} 35$ and $\mathrm{Cx} 36$, it remains to be determined which connexins form gap junctions in rods.

\section{Gap junctions within the synaptic terminal invagination}

The majority of Cx34.7 immunostaining was on the bases of cone pedicles, frequently deep within the central invagination in which synaptic contacts are made. Although some Cx35 staining was also found within the invaginating cavity, very little was closely apposed to the basal membrane, as delineated by SV2 staining. The close proximity of the Cx34.7 labeling to the basal membrane suggests that gap junctions may be formed between telodendria entering the central cavity and basal processes of the cone pedicle. Gap junctions have been observed between cone basal membranes and telodendria projecting into the invagination of chick cones (Cooper and McLaughlin, 1981). Such junctions have not been reported in fish; however, telodendria are well known to terminate within the complex of postsynaptic processes beneath fish cones (Sakai and Naka, 1983; Kraft and Burkhardt, 1986) as well as those of most nonmammalian vertebrates (Kolb, 1977; Kolb and Jones, 1984; Mariani and Lasansky, 1984). The small size of the gap junctions observed in chick telodendria suggests that such junctions could have been missed in some species. The physiological consequences of having some gap junctions much closer to synaptic sites than others is not known at this time and will require additional research to understand.

\section{Two distinct connexin-mediated pathways in the same circuit}

Both Cx35 and Cx34.7 are present where cone photoreceptors interact with other cones, either through gap junctions or through other types of junctions. Gap junctions among photoreceptors have a variety of apparent functions. Electrical coupling substantially reduces the variance of the photoresponse (Lamb and Simon, 1976), improving the signal/ noise ratio at the output synapse (Tessier-Lavigne and Attwell, 1988), particularly for large-field stimuli. Signal spread through
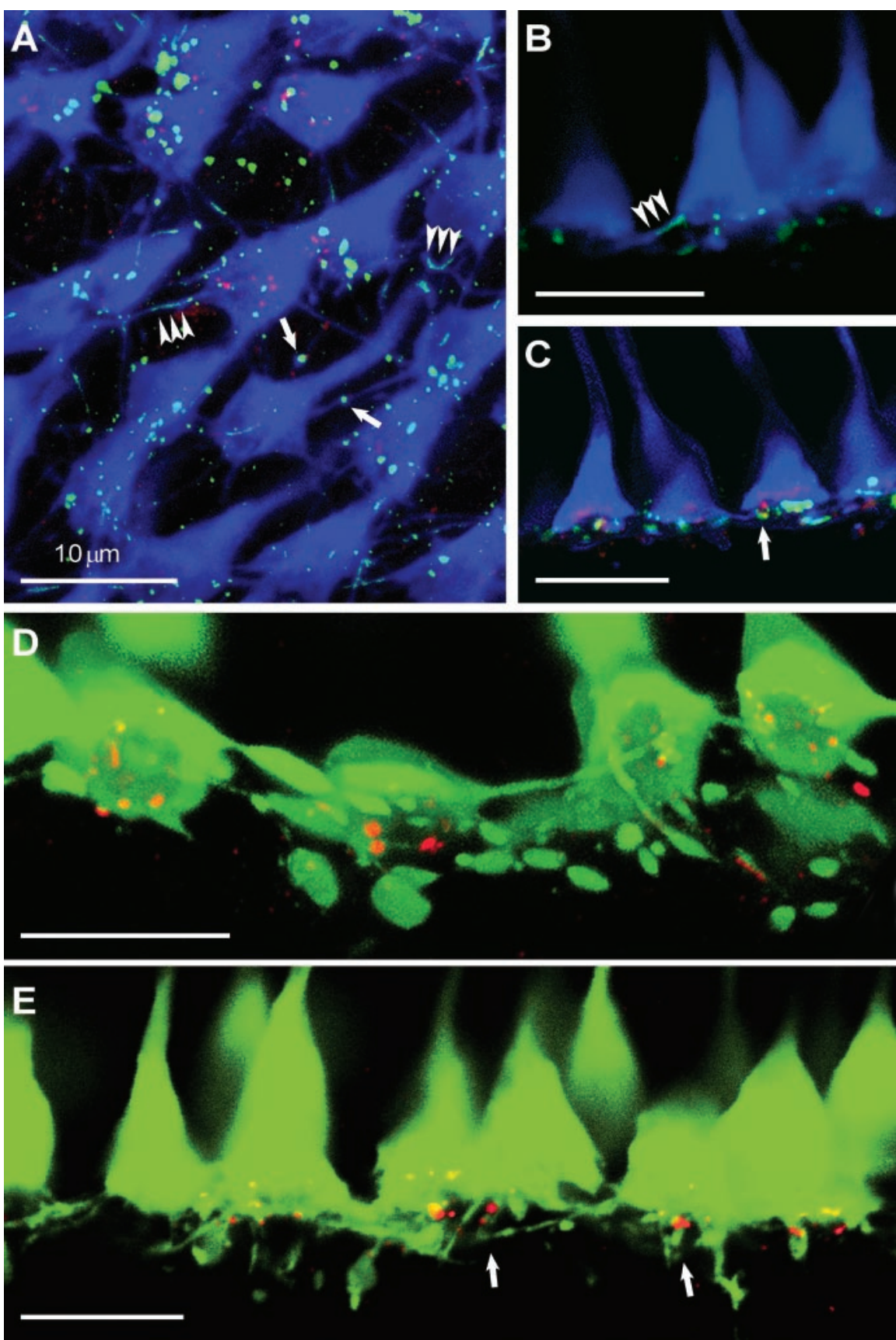

Figure 8. Gap junctions are located in the network of cone telodendria. $A$, Immunolabeling of double cones with FRet43 antibody (blue) reveals the network of telodendria connecting the cones. Cx35 immunostaining (green) is extensively colocalized with telodendria at linear plaques (triple arrowheads) and punctate spots indicative of crossing and tip-to-tip contacts (arrows). CX34.7 (red) is predominantly localized to the cone pedicles. Image is a $2.5 \mu \mathrm{m}$ confocal stack in whole-mount view. B, C, Vertical sections of cone terminals show telodendria that contact neighboring cones make gap junctions with $C \times 35$ in linear arrays (triple arrowheads). Telodendria may also enter the central invagination of a neighboring cone, where $\mathrm{C} \times 34.7$ plaques are located (arrow). Both images are $1.5 \mu \mathrm{m}$ confocal stacks. D, E, Double-labeled sections reveal $\mathrm{Cx} 34.7$ (red) association with cone telodendria matrix (green) more clearly. $\mathrm{C} \times 34.7$ plaques are scattered among the dense matrix of telodendria directly beneath each cone terminal. Small Cx34.7 plaques are located at the edges of elements of the matrix, whereas larger Cx34.7 plaques along telodendria appear to be located in areas from which the FRet43 antigen is excluded (arrows). $D$ is a $4 \mu \mathrm{m}$ confocal stack of an oblique section; $E, 1.0 \mu \mathrm{m}$ confocal stack of a vertical section. Scale bars, $10 \mu \mathrm{m}$.

gap junctions also allows strongly stimulated photoreceptors to use the output synapses of coupled photoreceptors (Attwell et al., 1987), expanding the response range of those photoreceptors encountering local stimuli. The effects of signal spread and noise reduction within an illuminated field have been shown to im- 
prove the detection of brightness boundaries (Lebedev et al., 1998). Any degradation of spatial information attributable to receptor coupling is very small and has recently been shown to be similar to the blur caused by the optics of the eye (DeVries et al., 2002).

The electrical effects of receptor coupling are intensitydependent. For example, Smith et al. (1986) have calculated that, in rod photoreceptors illuminated with a dim stimulus that excites a single rod, strong coupling shunts sufficient voltage away from the receptor to significantly degrade the performance of the output synapse. Reduction of coupling strength preserves the synapse function. To achieve optimal receptor function, electrical coupling must be modulated during the course of adaptation.

The presence of $\mathrm{Cx} 35$ and $\mathrm{Cx} 34.7$ gap junctions provides two distinct options for regulating the connectivity of cone photoreceptors. First, cytoplasmic cAMP levels regulate the opening of Cx35 gap junctions over at least a fivefold range, as measured by tracer diffusion. Thus, coupling may be increased in the light or in other conditions that reduce cAMP concentration. Under conditions of elevated cAMP, such as in dark-adapted photoreceptors, these gap junctions will be relatively uncoupled. Cx34.7 is present in fewer and smaller junctions and is located closer to the synaptic sites. This connexin may provide a pathway with different properties. Such a pathway would be useful to differentiate coupling between cones of the same spectral type and cones of different spectral types. Alternatively, Cx34.7 may provide a second pathway for coupling under conditions in which Cx35 is uncoupled. It will be important in the future to uncover the basis for the presence of these two distinct pathways.

Connexin 35 and its mammalian homolog, Cx36, are very widely distributed throughout the CNS and are very highly conserved (Condorelli et al., 1998; O’Brien et al., 1998; Rash et al., 2000). The present results suggest that gap junctions made of this connexin may be subject to dynamic regulation. Additional neuronal connexins, such as $\mathrm{Cx} 34.7$, provide a separate mechanism to adjust the level of coupling. Where intact cell-cell channels are formed, the co-occurrence of these two connexins will provide flexibility in maintaining a suitable level of coupling to optimize neuron function.

\section{References}

Attwell D, Borges S, Wu SM, Wilson M (1987) Signal clipping by the rod output synapse. Nature 328:522-524.

Bloomfield SA, Xin D, Osborne T (1997) Light-induced modulation of coupling between AII amacrine cells in the rabbit retina. Vis Neurosci 14:565-576.

Cohen AI, Todd RD, Harmon S, O’Malley KL (1992) Photoreceptors of mouse retinas possess D4 receptors coupled to adenylate cyclase. Proc Natl Acad Sci USA 89:12093-12097.

Condorelli DF, Parenti R, Spinella F, Salinaro AT, Belluardo N, Cardile V, Cicirata F (1998) Cloning of a new gap junction gene (Cx36) highly expressed in mammalian brain neurons. Eur J Neurosci 10:1202-1208.

Cooper NG, McLaughlin BJ (1981) Gap junctions in the outer plexiform layer of the chick retina: thin section and freeze-fracture studies. J Neurocytol 10:515-529.

Copenhagen DR, Green DG (1987) Spatial spread of adaptation within the cone network of turtle retina. J Physiol (Lond) 393:763-776.

Deans MR, Gibson JR, Sellitto C, Connors BW, Paul DL (2001) Synchronous activity of inhibitory networks in neocortex requires electrical synapses containing connexin36. Neuron 31:477-485.

Deans MR, Volgyi B, Goodenough DA, Bloomfield SA, Paul DL (2002) Connexin 36 is essential for transmission of rod-mediated visual signals in the mammalian retina. Neuron 36:703-712.

Dearry A, Burnside B (1985) Dopamine inhibits forskolin- and 3-isobutyl1-methylxanthine-induced dark-adaptive retinomotor movements in isolated teleost retinas. J Neurochem 44:1753-1763.
DeVries SH, Schwartz EA (1989) Modulation of an electrical synapse between solitary pairs of catfish horizontal cells by dopamine and second messengers. J Physiol (Lond) 414:351-375.

DeVries SH, Qi X, Smith R, Makous W, Sterling P (2002) Electrical coupling between mammalian cones. Curr Biol 12:1900-1907.

Draguhn A, Traub RD, Schmitz D, Jefferys JG (1998) Electrical coupling underlies high-frequency oscillations in the hippocampus in vitro. Nature 394:189-192.

Eckert R, Dunina-Barkovskaya A, Hulser DF (1993) Biophysical characterization of gap-junction channels in HeLa cells. Pflügers Arch 424:335-342.

Feigenspan A, Teubner B, Willecke K, Weiler R (2001) Expression of neuronal connexin36 in AII amacrine cells of the mammalian retina. J Neurosci 21:230-239.

Fujisawa H, Morioka H, Nakamura H, Watanabe K (1976) Gap junctions in the differentiated neural retinae of newly hatched chickens. J Cell Sci 22:597-606.

Gibson JR, Beierlein M, Connors BW (1999) Two networks of electrically coupled inhibitory neurons in neocortex. Nature 402:75-79.

Gold GH, Dowling JE (1979) Photoreceptor coupling in retina of the toad, Bufo marinus. I. Anatomy. J Neurophysiol 42:292-310.

Hampson EC, Vaney DI, Weiler R (1992) Dopaminergic modulation of gap junction permeability between amacrine cells in mammalian retina. J Neurosci 12:4911-4922.

Hormuzdi SG, Pais I, LeBeau FE, Towers SK, Rozov A, Buhl EH, Whittington MA, Monyer H (2001) Impaired electrical signaling disrupts gamma frequency oscillations in connexin 36-deficient mice. Neuron 31:487-495.

Kolb H (1977) The organization of the outer plexiform layer in the retina of the cat: electron microscopic observations. J Neurocytol 6:131-153.

Kolb H, Jones J (1984) Synaptic organization of the outer plexiform layer of the turtle retina: an electron microscope study of serial sections. J Neurocytol 13:567-591.

Kolb H, Jones J (1985) Electron microscopy of Golgi-impregnated photoreceptors reveals connections between red and green cones in the turtle retina. J Neurophysiol 54:304-317.

Kraft TW, Burkhardt DA (1986) Telodendrites of cone photoreceptors: structure and probable function. J Comp Neurol 249:13-27.

Krizaj D, Gabriel R, Owen WG, Witkovsky P (1998) Dopamine D2 receptor-mediated modulation of rod-cone coupling in the Xenopus retina. J Comp Neurol 398:529-538.

Lamb TD, Simon EJ (1976) The relation between intercellular coupling and electrical noise in turtle photoreceptors. J Physiol (Lond) 263:257-286.

Larison KD, Bremiller R (1990) Early onset of phenotype and cell patterning in the embryonic zebrafish retina. Development 109:567-576.

Lasater EM (1987) Retinal horizontal cell gap junctional conductance is modulated by dopamine through a cyclic AMP-dependent protein kinase. Proc Natl Acad Sci USA 84:7319-7323.

Lebedev DS, Byzov AL, Govardovskii VI (1998) Photoreceptor coupling and boundary detection. Vision Res 38:3161-3169.

Lee EJ, Han JW, Kim HJ, Kim IB, Lee MY, Oh SJ, Chung JW, Chun MH (2003) The immunocytochemical localization of connexin 36 at rod and cone gap junctions in the guinea pig retina. Eur J Neurosci 18:2925-2934.

MacVicar BA, Dudek FE (1981) Electrotonic coupling between pyramidal cells: a direct demonstration in rat hippocampal slices. Science 213:782-785.

Maier N, Guldenagel M, Sohl G, Siegmund H, Willecke K, Draguhn A (2002) Reduction of high-frequency network oscillations (ripples) and pathological network discharges in hippocampal slices from connexin 36-deficient mice. J Physiol (Lond) 541:521-528.

Mariani AP, Lasansky A (1984) Chemical synapses between turtle photoreceptors. Brain Res 310:351-354.

Mills SL, Massey SC (1995) Differential properties of two gap junctional pathways made by AII amacrine cells. Nature 377:734-737.

Mills SL, Massey SC (1998) The kinetics of tracer movement through homologous gap junctions in the rabbit retina. Vis Neurosci 15:765-777.

Mills SL, O'Brien JJ, Li W, O'Brien J, Massey SC (2001) Rod pathways in the mammalian retina use connexin36. J Comp Neurol 436:336-350.

Nir I, Harrison JM, Haque R, Low MJ, Grandy DK, Rubinstein M, Iuvone PM (2002) Dysfunctional light-evoked regulation of cAMP in photoreceptors and abnormal retinal adaptation in mice lacking dopamine D4 receptors. J Neurosci 22:2063-2073. 
O’Brien J, Bruzzone R, White TW, Al-Ubaidi MR, Ripps H (1998) Cloning and expression of two related connexins from the perch retina define a distinct subgroup of the connexin family. J Neurosci 18:7625-7637.

Pereda A, O’Brien J, Nagy JI, Bukauskas F, Davidson KG, Kamasawa N, Yasumura T, Rash JE (2003) Connexin35 mediates electrical transmission at mixed synapses on Mauthner cells. J Neurosci 23:7489-7503.

Piccolino M, Neyton J, Gerschenfeld HM (1984) Decrease of gap junction permeability induced by dopamine and cyclic adenosine $3^{\prime}: 5^{\prime}$ monophosphate in horizontal cells of turtle retina. J Neurosci 4:2477-2488.

Rash JE, Staines WA, Yasumura T, Patel D, Furman CS, Stelmack GL, Nagy JI (2000) Immunogold evidence that neuronal gap junctions in adult rat brain and spinal cord contain connexin-36 but not connexin-32 or connexin-43. Proc Natl Acad Sci USA 97:7573-7578.

Raviola E, Gilula NB (1973) Gap junctions between photoreceptor cells in the vertebrate retina. Proc Natl Acad Sci USA 70:1677-1681.

Ribelayga C, Wang Y, Mangel SC (2002) Dopamine mediates circadian clock regulation of rod and cone input to fish retinal horizontal cells. J Physiol (Lond) 544:801-816.

Rorig B, Klausa G, Sutor B (1995) Dye coupling between pyramidal neurons in developing rat prefrontal and frontal cortex is reduced by protein kinase A activation and dopamine. J Neurosci 15:7386-7400.

Sakai H, Naka KI (1983) Synaptic organization involving receptor, horizontal and on- and off-center bipolar cells in the catfish retina. Vision Res 23:339-351.

Scholes JH (1975) Colour receptors, and their synaptic connexions, in the retina of a cyprinid fish. Philos Trans R Soc Lond B Biol Sci 270:61-118.

Schwartz EA (1975a) Rod-rod interaction in the retina of the turtle. J Physiol (Lond) 246:617-638.

Schwartz EA (1975b) Cones excite rods in the retina of the turtle. J Physiol (Lond) 246:639-651.

Smith RG, Freed MA, Sterling P (1986) Microcircuitry of the dark-adapted cat retina: functional architecture of the rod-cone network. J Neurosci 6:3505-3517.

Stella Jr SL, Thoreson WB (2000) Differential modulation of rod and cone calcium currents in tiger salamander retina by D2 dopamine receptors and cAMP. Eur J Neurosci 12:3537-3548.

Suzuki S, Kaneko A (1990) Identification of bipolar cell subtypes by protein kinase C-like immunoreactivity in the goldfish retina. Vis Neurosci 5:223-230.

Teranishi T, Negishi K, Kato S (1983) Dopamine modulates S-potential amplitude and dye-coupling between external horizontal cells in carp retina. Nature 301:243-246.

Tessier-Lavigne M, Attwell D (1988) The effect of photoreceptor coupling and synapse nonlinearity on signal:noise ratio in early visual processing. Proc R Soc Lond B Biol Sci 234:171-197.

Teubner B, Degen J, Sohl G, Guldenagel M, Bukauskas FF, Trexler EB, Verselis VK, De Zeeuw CI, Lee CG, Kozak CA, Petrasch-Parwez E, Dermietzel R, Willecke K (2000) Functional expression of the murine connexin 36 gene coding for a neuron-specific gap junctional protein. J Membr Biol 176:249-262.

Veruki ML, Hartveit E (2002) AII (Rod) amacrine cells form a network of electrically coupled interneurons in the mammalian retina. Neuron 33:935-946.

Wang Y, Mangel SC (1996) A circadian clock regulates rod and cone input to fish retinal cone horizontal cells. Proc Natl Acad Sci USA 93:4655-4660.

Witkovsky P, Shakib M, Ripps H (1974) Interreceptoral junctions in the teleost retina. Invest Ophthalmol 13:996-1009.

Witkovsky P, Burkhardt DA, Nagy AR (1979) Synaptic connections linking cones and horizontal cells in the retina of the pikeperch (Stizostedion vitreum). J Comp Neurol 186:541-559.

Wu SM, Yang XL (1988) Electrical coupling between rods and cones in the tiger salamander retina. Proc Natl Acad Sci USA 85:275-278.

Yang XL, Wu SM (1989) Modulation of rod-cone coupling by light. Science 244:352-354.

Yazulla S, Studholme KM (2001) Neurochemical anatomy of the zebrafish retina as determined by immunocytochemistry. J Neurocytol 30:551-592.

Zimmerman AL, Rose B (1985) Permeability properties of cell-to-cell channels: kinetics of fluorescent tracer diffusion through a cell junction. J Membr Biol 84:269-283. 